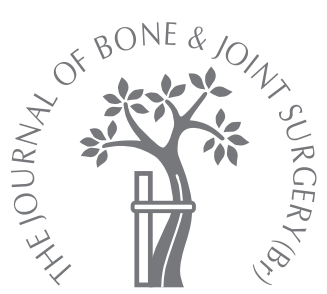

M. Hasegawa,

A. Sudo,

A. Uchida

From Mie University

Graduate School of

Medicine, Mie, Japan

\title{
Alumina ceramic-on-ceramic total hip replacement with a layered acetabular component
}

M. Hasegawa, MD, PhD, Assistant Professor

A. Sudo, MD, PhD, Lecturer

A. Uchida, MD, PhD,

Professor, Chairman

Department of Orthopaedic

Surgery

Mie University Graduate

School of Medicine, 2-174

Edobashi, Tsu City, Mie 514

8507, Japan

Correspondence should be sent to Dr M. Hasegawa; e-mail:

masahase@

clin.medic.mie-u.ac.jp

(C2006 British Editorial Society of Bone and Joint Surgery doi:10.1302/0301-620X.88B7.

$17675 \$ 2.00$

$J$ Bone Joint Surg [Br]

2006;88-B:877-82.

Received 23 January 2006;

Accepted after revision

30 March 2006

A modular layered acetabular component (metal-polyethylene-ceramic) was developed in Japan for use in alumina ceramic-on-ceramic total hip replacement. Between May 1999 and July 2000, we performed 35 alumina ceramic-on-ceramic total hip replacements in $\mathbf{3 0}$ consecutive patients, using this layered component and evaluated the clinical and radiological results over a mean follow-up of 5.8 years (5 to 6.5). A total of six hips underwent revision, one for infection, two for dislocation with loosening of the acetabular component, two for alumina liner fractures and one for component dissociation with pelvic osteolysis. There were no fractures of the ceramic heads, and no loosening of the femoral or acetabular component in the unrevised hips was seen at final follow-up. Osteolysis was not observed in any of the unrevised hips. The survivorship analysis at six years after surgery was $83 \%$. The layered acetabular component in our experience, has poor durability because of unexpected mechanical failures including alumina liner fracture and component dissociation.

Alumina ceramic components have been used in total hip replacement (THR) for over 30 years in an attempt to decrease problems associated with polyethylene wear. The main limitations of these components are the risk of fracture and failure of acetabular component fixation. ${ }^{1-4}$ Advances in the manufacturing process of ceramics during the last decade have led to the production of ceramics with high purity, high density and smaller grain size, all of which reduce the risk of fracture of a component. ${ }^{5}$ Consequently, fixation of the acetabular component has become the weak link in alumina-on-alumina THR. Cemented alumina ceramic components have a high rate of loosening which appears to be because of a modulus mismatch between the alumina component and the bone or cement. ${ }^{1,3,6}$

A number of techniques to improve fixation of the acetabular component have been reported. ${ }^{3,7}$ However, the most promising technique seems to be the uncemented metalbacked alumina component with porous coating, as demonstrated by the excellent mid-term results of Bizot et al. ${ }^{7}$ Another technique suggests the use of a modular acetabular component with a layered insertion (alumina ceramicpolyethylene-titanium) to improve fixation. In this technique, the layer of polyethylene between the ceramic liner and the metal shell could prevent impingement between the rim of the liner and the metal femoral neck. It would also reduce the stiffness of the ceramic-onceramic couple, perhaps leading to increased longevity of the artificial joint. The present study evaluates the medium-term clinical results of a consecutive series of primary ceramic-on-ceramic THRs with a layered acetabular component.

\section{Patients and Methods}

Between May 1999 and July 2000, 35 primary uncemented ceramic-on-ceramic THRs with a layered component (Kyocera, Kyoto, Japan) were performed in 30 consecutive patients, all of whom were women with a mean age of 63 years (45 to 86) and a mean weight of $50 \mathrm{~kg}$ (40 to 64 ). The pre-operative diagnosis was osteoarthritis, including developmental dysplasia in 30 hips, rheumatoid arthritis in three and septic arthritis in two. All the operations were performed by the same surgeon (AS) via a posterior approach. One patient died from unrelated causes within five years of the operation and a further patient was lost to followup. The remaining 28 patients (33 hips) were evaluated after a mean follow-up of 5.8 years (5 to 6.5 ).

The uncemented acetabular component (Fig. 1) consisted of a titanium alloy metal shell and an alumina-bearing surface liner consisting of an alumina ceramic liner and an ultra- 


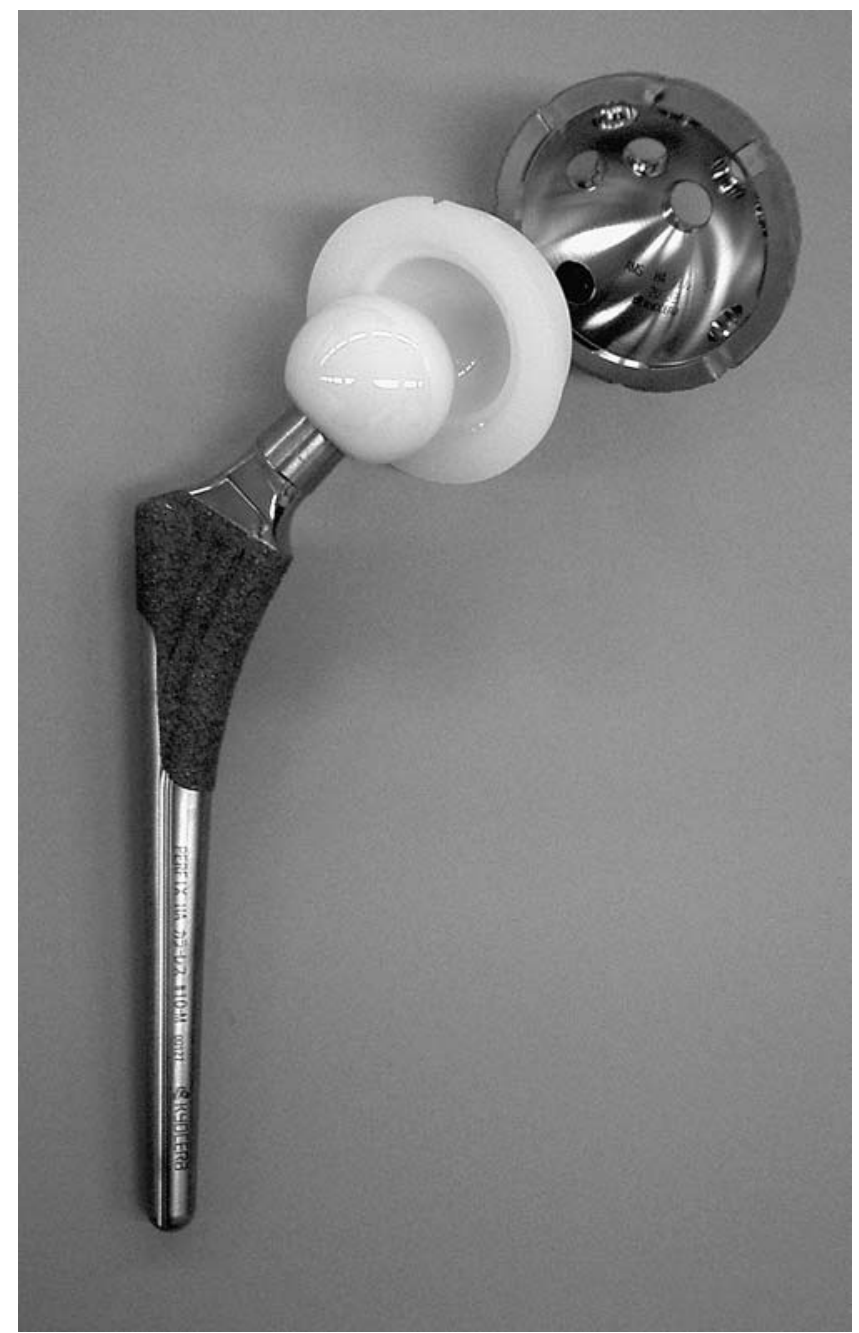

Fig. 1

Photograph showing the Kyocera total hip system.

Table I. The distribution of different-sized metal shells

\begin{tabular}{ll}
\hline Diameter $(\mathbf{m m})$ & Number of hips \\
\hline 46 & 7 \\
48 & 6 \\
50 & 4 \\
52 & 9 \\
54 & 6 \\
56 & 3 \\
\hline
\end{tabular}

high-molecular-weight polyethylene shell. The ceramic liner was mechanically-fixed to the polyethylene liner and the liner was then inserted into the metal shell at surgery and held together via a locking mechanism. The surface of the metal shell was porous-coated with pure titanium using an inert gas shielded arc spray and, subsequently, a hydroxyapatite coating was applied to the porous area. ${ }^{8}$ The metal shell was fixed with titanium screws to ensure primary stability. The outer diameter of the metal shell varied (Table I). The thickness of the alumina liner was $4 \mathrm{~mm}$ and the thickness of the polyethylene varied from only $2 \mathrm{~mm}$ to $9 \mathrm{~mm}$ depending on the size of the metal-backed component. The femoral component was a Perfix hydroxyapatite collarless stem (Kyocera, Kyoto, Japan) made of titanium alloy and was proximally porous-coated. The head was $28 \mathrm{~mm}$ in diameter and made of alumina ceramic, secured with a morse taper. In ten hips an acetabular autograft was used to fill a bony defect. Partial weight-bearing was allowed on the seventh post-operative day and full weight-bearing at three months post-operatively.

The clinical results were analysed using the Merle d'Aubigné and Postel scoring system. ${ }^{9}$ Serial radiographs were obtained and analysed by an independent observer $(\mathrm{MH})$. The inclination of the acetabular component was measured and the presence of radiolucent lines was evaluated using the zones described by DeLee and Charnley ${ }^{10}$ for the acetabular component and Gruen, McNeice and Amstutz ${ }^{11}$ for the femoral component. Radiological loosening of the acetabular component was evaluated using the method of Hodgkinson, Shelley and Wroblewski, ${ }^{12}$ loosening being defined as migration or radiolucency greater than $1 \mathrm{~mm}$ in all the DeLee and Charnley zones. ${ }^{10}$ Radiological loosening of the femoral component was evaluated using the method described by Engh, Bobyn and Glassman. ${ }^{13}$ Linear wear of the acetabular component was determined by measuring the change in the shortest distance between the centre of the femoral head and the periphery of the acetabular component and by comparing the immediate postoperative radiograph with that taken at the last follow-up visit, as described by Livermore, Ilstrup and Morrey. ${ }^{14}$ The measurements were taken using calipers with an accuracy of $0.5 \mathrm{~mm}$. Peri-prosthetic cystic or scalloped lesions with a diameter greater than $2 \mathrm{~mm}$ which were not present on the immediate post-operative radiograph were defined as osteolysis. Heterotopic ossification was classified according to the system of Brooker et al. ${ }^{15}$ The intra-observer error was less than $0.5 \mathrm{~mm}$.

Statistical analysis was performed using the Wilcoxon signed rank test. A p value of 0.05 was considered to be significant. Kaplan-Meier survivorship analysis was performed using revision for any reason as the end-point.

\section{Results}

At the final follow-up, six patients (six hips) had undergone revision with a mean duration between the initial operation and the revision of 1.7 years (0.2 to 3.4). Of these, one hip underwent a two-stage revision because of infection. In two patients, the acetabular component was revised to a metalon-polyethylene design because of recurrent dislocation with loosening; a polyethylene liner was implanted into the new metal shell, and the ceramic head was replaced with a metal head. 


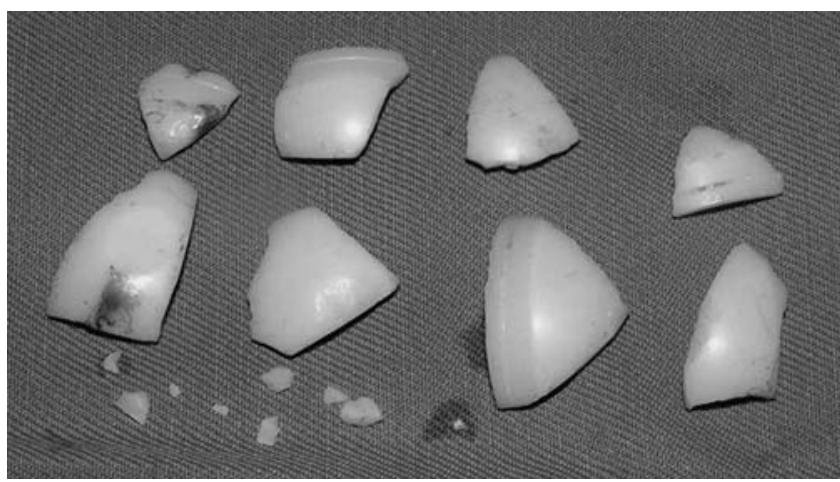

Fig. 2

Photograph showing the comminuted fracture of the alumina liner.

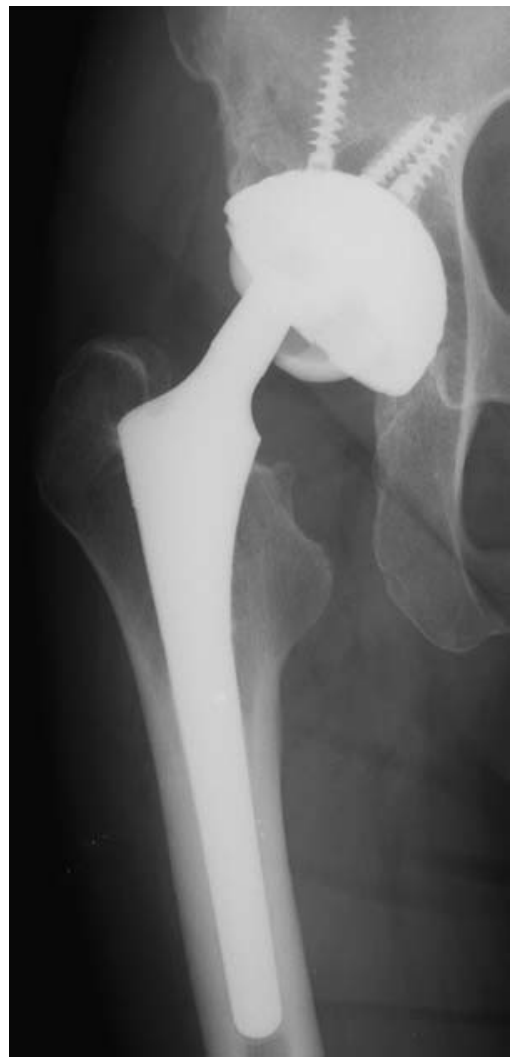

Fig. 3

Anteroposterior radiograph showing acetabular component dissociation. The alumina head is positioned eccentrically within the acetabular metal shell. The alumina liner is dissociated inferiorly from the shell.

Alumina liner fractures occurred in two hips without trauma (two patients) and these were revised at 1.5 and 2.5 years after the initial operation, respectively (Fig. 2). In both patients, the acetabular and the femoral components were well-fixed, and were not revised. An extensive

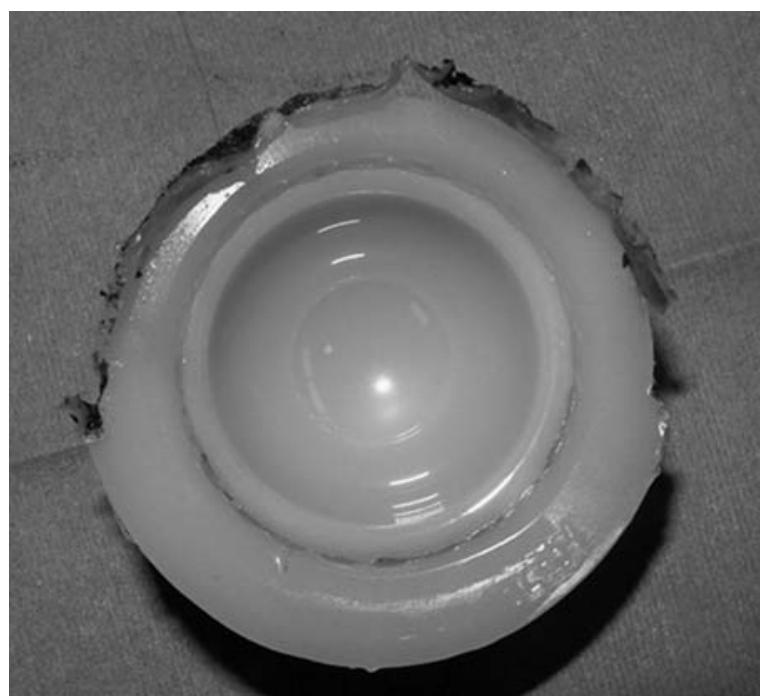

Fig. 4a

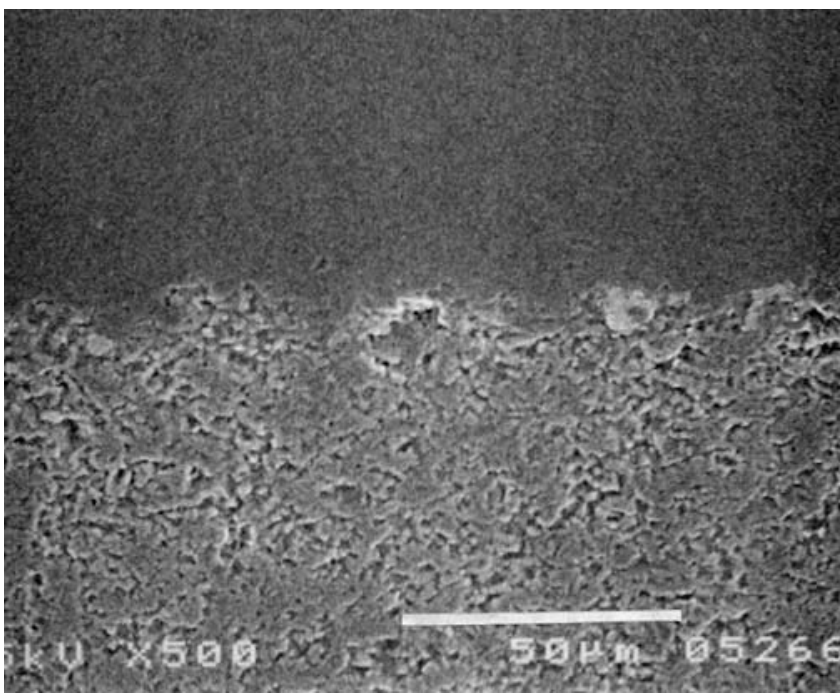

Fig. 4b

Retrieved alumina-bearing surface liner showing a) more than half of the polyethylene rim around the locking notch worn away, and b) scanning electron micrograph of the dissociated liner (magnification x 500) showing the worn articulating surface in the peripheral portion of the alumina liner, suggesting edge loading.

debridement and synovectomy was undertaken in both hips to remove as much of the ceramic debris as possible and a new metal head (cobalt-chromium alloy) with a polyethylene liner was implanted. However, one hip exhibited signs of catastrophic wear of the cobalt-chromium femoral head after two years ${ }^{16}$ and underwent a thorough debridement with removal of all the components. This was revised to a ceramic-on-polyethylene couple to avoid increased wear. The other patient with the alumina fracture had an uneventful post-operative course and was able to return to full activity. However, the patient died two years after the revision, from an unrelated cause. 
The final patient who underwent a revision sustained an acetabular component dissociation after a fall 3.4 years after the initial operation (Fig. 3). The metal shell had a diameter of $54 \mathrm{~mm}$ and the component position was satisfactory. However, there was acetabular osteolysis, and intra-operative assessment revealed that the alumina-bearing surface liner was disengaged inferiorly from the metal shell. More than half of the marginal part of the circumference of the polyethylene liner was shaved off, and pulled out of the locking notch (Fig. 4a). Scanning electron microscopy (S-3000N; Hitachi, Tokyo, Japan) showed surface damage in the peripheral portion of the alumina inlay. Massive material excavation was observed at the area of edge loading (Fig. 4b). The superolateral portion of the alumina head was also worn. The alumina inlay exhibited no obvious fractures. The femoral and acetabular components were left in place and curettage of pelvic osteolysis was performed via the screw holes. Subsequently, a polyethylene liner was cemented into the well-fixed metal shell. A cobaltchromium femoral head was used. Histological examination of the granulation tissue from the pelvis revealed numerous macrophages and foreign body granulomas, consisting of giant cells and polyethylene particles. The patient remained asymptomatic at the last follow-up, 2.5 years after revision.

Complications in the remaining 27 hips included dislocation in one, which was not recurrent, and heterotopic ossification in three Brooker $^{15} \mathrm{I}$ in one hip, and Brooker III in two). No other fractures of the alumina head were seen.

The Kaplan-Meier survivorship analysis revealed a sixyear survival rate of $83 \%$ (95\% confidence interval, 77 to $89)$ with revision for any cause as the end-point. The clinical results of the 22 patients (27 hips) who did not undergo revision revealed that the mean Merle d'Aubigné and Postel score for this group had improved significantly from 9.1 points (4 to 13 ) pre-operatively to 15.7 (13 to 18 ) (p < 0.001 ) post-operatively. The mean scores for pain, mobility and walking ability improved from 3.3 (0 to 4 ), 4.1 (0 to 6) and 1.7 ( 0 to 4 ) pre-operatively to 6.0 (5 to 6 ), 5.6 (5 to 6 ), and 4.1 (2 to 6 ) at the last follow-up, respectively. None of the patients reported any pain in the thigh.

Radiological findings revealed that the mean inclination angle of the acetabular component was $49^{\circ}\left(32^{\circ}\right.$ to $\left.60^{\circ}\right)$. Of the 27 hips which were not revised, four had a radiolucent line in zone 1 on the acetabular side according to the classification of DeLee and Charnley. ${ }^{10}$ On the femoral side, four had a radiolucent line in Gruen zone 2, 11 in zone 3, 17 in zone 4 , nine in zone 5 , and three in zone 6 , but none had a radiolucent line in the proximal anchoring area (zone 1 or 7$).{ }^{11}$ Some hips had lesions in more than one zone. None of the radiolucent lines was wider than $2 \mathrm{~mm}$. Loosening of the acetabular component was not observed in any of the unrevised hips. All of the femoral components exhibited radiological evidence of bone ingrowth ${ }^{13}$ at the last follow-up. There was no radiological evidence of ceramic wear at the last follow-up visit. None of the unrevised hips exhibited osteolysis.

\section{Discussion}

The advantages of an alumina ceramic-on-ceramic couple in relation to outcome after THR has not been established. The main cause for failure of the cemented alumina component has been acute debonding at the implantcement interface. ${ }^{1,4,6}$ This has led to the use of uncemented all-alumina components. However, it was found that there was no bone directly in contact with the implant and an intermediate fibrous layer had developed between the implant and the host bone. ${ }^{2,3,6}$ Recently, Bizot et $\mathrm{al}^{7}$ reported favourable results for a press-fit uncemented porous-coated component with an alumina insert. However, impingement at the extremes of hip movement between the neck of the femoral component and the rim of a ceramic acetabular bearing could lead to chipping or fracture of the ceramic, or scoring of the metal femoral neck (from contact with the harder ceramic material), with the latter condition increasing the risk of failure of the femoral neck. Recessing a ceramic acetabular liner in a metal shell protects the liner by preventing neck impingement and edge loading of the ceramic material. ${ }^{17}$ However, the use of a recessed metallic shell carries the risk of wear of the femoral neck generating metallic debris. In a minimum five-year follow-up study of metal-backed uncemented components with an alumina insert, Bizot et $\mathrm{al}^{7}$ reported a rim fracture of the ceramic liner in only one of 234 THRs, possibly because of trauma. The survival rate after nine years was $93 \%$, with revision as the end-point. In another study by Yoo et al, ${ }^{18}$ one of 100 THRs with a metal-backed alumina socket sustained a peripheral chip fracture of the alumina acetabular insert and an alumina femoral head fracture four years post-operatively following trauma. A study by D'Antonio et al, ${ }^{17}$ reported no ceramic fractures in 222 metal-backed alumina acetabular components, but peripheral chips were found in four ceramic liners because of technical problems involving the placement of the inserts within the metal shell. These results, with a follow-up of more than five years, indicate that modular alumina acetabular liner fracture does not generally occur without a chip fracture.

The layered acetabular component used in this series was developed in Japan and became commercially-available in 1998. Medium-term results of the ceramic-onceramic THR with a layered component have been poor. These acetabular components have been associated with unexpected mechanical failure, alumina liner fracture and dissociation. The ceramic layered component was withdrawn from the market in 2000 because of such mechanical failures. ${ }^{19-21}$ To date, 3933 ceramic layered acetabular components have been implanted in Japan and we are aware of 117 alumina liner fractures $(3 \%)$ and 224 dissociations $(6 \%)$ which have been reported to the manufacturer. The mean weight of the patients in our study was 
low. However, we anticipate that the problems observed in our patients are likely to be more frequent and more severe in patients with increased weight. Fracture of the ceramic components has been, and remains, the main concern for patients and surgeons. In the early development of ceramic hips, the rate of fracture was unacceptably high, reaching $13 \% .^{2,22}$ This has been reduced by an improvement in the quality of alumina and quality control. Willmann ${ }^{23}$ reported the results for the Biolox femoral head (Ceramtec AG, Stuttgart, Germany), for which the first-generation component fracture rate was $0.026 \%$, reducing to $0.004 \%$ for the third generation. In the present series, the superior rim of the ceramic liner was impacted by the femoral head, and cracks in the ceramic liner propagated from the margin of the liner. We did not find any flaws in the material from the retrieved alumina implants. This would suggest that the cause of the fracture was stress concentration or edge loading at the superior rim of the ceramic liner. ${ }^{19}$ The thickness of the alumina liner was only $4 \mathrm{~mm}$. Biomechanical tests on the alumina-bearing surface liner have shown a fracture strength of more than $70 \mathrm{kN}$ under standard conditions. However, the strength decreases to $5 \mathrm{kN}$ under edge loading. ${ }^{19}$ Ceramic-on-ceramic components, although very strong, should be placed at an angle of $\leq 45^{\circ}$ on the acetabular side to distribute forces over the greatest surface area of the femoral head and acetabular component. Minimising rim overload with horizontal placement may reduce the rate of late fractures of the ceramic rim. ${ }^{24}$ Alumina liner dissociation may be caused by a strong rotational torque because of roughening of the alumina bearing surface, although the co-efficient of friction of the original aluminaon-alumina articulation should be very low. In vitro work has shown that the co-efficient of friction of the aluminaon-alumina articulation is 0.007 , which is lower than that measured for a metal-on-polyethylene articulation (0.011). ${ }^{25}$ In the present study, we observed severe wear in the peripheral portion of the alumina inlay and the superolateral portion of the alumina head. Roughening of the worn articulating surface may cause a strong torque. Wear on the alumina component and head may be because of edge loading caused by microseparation of the bearing centres. ${ }^{20,26}$ If a hydrophobic material (polyethylene) is mixed with a hydrophilic one (alumina) in a wet medium, water may enter between the two materials. This could be the initiating factor for dissociation. Ravasi and Sansone $\mathrm{e}^{27}$ have reported a five-year satisfactory outcome of 56 THRs with a ceramic layered acetabular component. Any concern about polyethylene wear at the interface with the metal shell was minimised in their study by the use of the morse cone for attaching the polyethylene liner to the metal shell, this appears to give a very stable interface. In addition, a small acetabular component (outer diameter $<48 \mathrm{~mm}$ ) was not used for these patients. Also, no alumina fracture or component dissociation was observed. However, in our study, small acetabular components were used, including some with an outer diameter of $46 \mathrm{~mm}$, and the compo- nent contained thin ceramic and polyethylene layers. The use of a small component may increase the risk of mechanical failure. Even with a metal-backed alumina acetabular component without a polyethylene layer, studies indicate that the risk of component fracture is greatly decreased by the use of a metal shell with an outer diameter of $\geq 50$ mm. ${ }^{7}$

Controversy exists regarding the treatment of ceramic component fractures. Allain et $\mathrm{al}^{28}$ have reported the results of a short-term (mean follow-up, 3.5 years) multicentre study of 105 patients who underwent revision surgery to treat a fracture of the ceramic head. Even if the head appeared macroscopically normal after a thorough debridement, microscopic ceramic particles could produce thirdbody wear and the authors therefore recommended against the use of a stainless-steel femoral head. They also speculated that the use of a cobalt-chromium femoral head could prevent abrasive wear, which occurred with stainless-steel heads in their series. However, our findings indicate that the catastrophic wear of the cobalt-chromium femoral head was caused by alumina particles in the periprosthetic soft tissues which were in contact with the articular surface, leading to metallosis. ${ }^{16}$ For revision hip replacement after a ceramic fracture, we recommend removal of all the components and use of an alumina-on-alumina or ceramic-on-polyethylene bearing, to avoid third-body wear and damage to the metal by ceramic particles. However, we do acknowledge that removal of a well-fixed femoral component can be a complex surgical procedure that could cause damage and depletion of bone stock.

One fundamental advantage of the ceramic-on-ceramic bearings is their excellent resistance to wear, which minimises the risk of osteolysis. The incidence of osteolysis after modern alumina ceramic-on-ceramic THR has been found to range between $0 \%$ and $1.4 \% .^{17,18,28}$ However, layered acetabular components introduce the possibility of polyethylene wear from the back or rim of the liner, possibly causing osteolysis in an otherwise polyethylene-free joint. If the locking mechanism fails, the convex liner surface and the rim of the liner may become a source of polyethylene debris contributing to osteolysis. Therefore, the presence of pelvic osteolysis may predict dissociation with this type of acetabular component.

Our findings indicate that the layered acetabular component has poor durability, as indicated by the rates of alumina liner fracture and dissociation. Since the femoral head seems to separate from the acetabular component during gait, an in vitro experimental procedure before use in patients could not predict the mode of failure. In vivo hip joint kinematics and accurate wear performance need to be studied as well. We remain concerned that the rates of alumina liner fracture and acetabular component dissociation may increase with time.

We wish to thank Masaru Ueno, PhD, from Japan Medical Materials, Osaka, Japan, for providing technical assistance during the analysis of the retrieved prostheses. 
No benefits in any form have been received or will be received from a commercial party related directly or indirectly to the subject of this article.

\section{References}

1. Nizard RS, Sedel L, Christel P, et al. Ten-year survivorship of cemented ceramicceramic total hip prosthesis. Clin Orthop 1992;282:53-63.

2. Boehler M, Knahr K, Plenk H Jr, et al. Long-term results of uncemented alumina acetabular implants. J Bone Joint Surg [Br] 1994;76-B:53-9.

3. Hamadouche M, Nizard RS, Meunier A, Bizot P, Sedel L. Cementless bulk alumina socket: preliminary results at 6 years. J Arthroplasty 1999;14:701-7.

4. Sedel L, Nizard RS, Kerboull L, Witvoet J. Alumina-alumina hip replacement in patients younger than 50 years old. Clin Orthop 1994;298:175-83.

5. Bierbaum E, Nairus J, Kuesis D, Morrison JC, Ward D. Ceramic-on-ceramic bearings in total hip arthroplasty. Clin Orthop 2002;405:158-63.

6. Hamadouche M, Boutin P, Daussange J, Bolander ME, Sedel L. Alumina-onalumina total hip arthroplasty: a minimum 18.5-year follow-up study. J Bone Joint Surg $[A m]$ 2002;84-A:69-77.

7. Bizot P, Larrouy M, Witvoet J, Sedel L, Nizard R. Press-fit metal-backed alumina sockets: a minimum 5-year followup study. Clin Orthop 2000;379:143-42.

8. Nakashima Y, Hayashi K, Inadome T, et al. Hydroxyapatite-coating on titanium arc sprayed titanium implants. J Biomed Mater Res 1997;35:287-98.

9. Merle d'Aubigné R, Postel M. Functional results of hip arthroplasty with acrylic prosthesis. J Bone Joint Surg [Am] 1954;36-A:451-75.

10. DeLee JG, Charnley J. Radiological demarcation of cemented sockets in total hip replacement. Clin Orthop 1976;121:20-32.

11. Gruen TA, McNeice GM, Amstutz HC. "Modes of failure" of cemented stem-type femoral components: a radiographic analysis of loosening. Clin Orthop 1979;141:17-27.

12. Hodgkinson JP, Shelley P, Wroblewski BM. The correlation between the roentgenographic appearance and operative findings at the bone-cement junction of the socket in Charnley low friction arthroplasties. Clin Orthop 1988;228:105-9.

13. Engh CA, Bobyn JD, Glassman AH. Porous-coated hip replacement: the factors governing bone ingrowth, stress shielding, and clinical results. J Bone Joint Surg [Br] 1987;69-B:45-55
14. Livermore J, Ilstrup D, Morrey B. Effect of femoral head size on wear of the polyethylene acetabular component. J Bone Joint Surg [Am] 1990;72-A:518-28.

15. Brooker AF, Bowerman JW, Robinson RA, Riley LH Jr. Ectopic ossification following total hip replacement: incidence and a method of classification. J Bone Joint Surg [Am] 1973;55-A:1629-32.

16. Hasegawa M, Sudo A, Uchida A. Cobalt-chromium head wear following revision hip arthroplasty performed after ceramic fracture: a case report. Acta Orthopaedica 2006:in press.

17. D'Antonio J, Capello W, Manley M, Naughton M, Sutton K. Alumina ceramic bearings for total hip arthroplasty: five-year results of a prospective randomized study. Clin Orthop 2005;436:164-71.

18. Yoo JJ, Kim YM, Yoon KS, et al. Alumina-on-alumina total hip arthroplasty: a fiveyear minimum follow-up study. J Bone Joint Surg [Am] 2005;87-A:530-5.

19. Hasegawa M, Sudo A, Hirata H, Uchida A. Ceramic acetabular liner fracture in total hip arthroplasty with a ceramic sandwich cup. J Arthroplasty 2003;18:658-61.

20. Akagi M, Nonaka T, Nishisaka F, et al. Late dissociation of an alumina-on-alumina bearing modular acetabular component. J Arthroplasty 2004;19:647-51.

21. Yamamoto K, Shishido T, Tateiwa T, et al. Failure of ceramic THR with liner dislocation: a case report. Acta Orthop Scand 2004;75:500-2

22. Fritsch EW, Gleitz M. Ceramic femoral head fractures in total hip arthroplasty. Clin Orthop 1996;328:129-36.

23. Willmann G. Ceramic femoral head retrieval data. Clin Orthop 2000;379:22-8.

24. Garino JP. Modern ceramic-on-ceramic total hip systems in the United States: early results. Clin Orthop 2000;379:41-7.

25. Saikko V, Pfaff HG. Low wear and friction in alumina/alumina total hip joints: a hip simulator study. Acta Orthop Scand 1998;69:443-8.

26. Nevelos J, Ingham E, Doyle C, et al. Microseparation of the centers of aluminaalumina artificial hip joints during simulator testing produces clinically relevant wear rates and patterns. J Arthroplasty 2000:15:793-5.

27. Ravasi F, Sansone V. Five-year follow-up with a ceramic sandwich cup in total hip replacement. Arch Orthop Trauma Surg 2002;122:350-3.

28. Allain J, Roudot-Thoraval F, Delecrin J, et al. Revision total hip arthroplasty performed after fracture of a ceramic femoral head: a multicenter survivorship study. J Bone Joint Surg [Am] 2003;85-A:825-30 